\title{
Cirrus cloud radiative characteristics from continuous MPLNET profiling at GSFC in 2012
}

\author{
S. Lolli ${ }^{*}$, J. R. Lewis ${ }^{1}$, J. R. Campbell ${ }^{2}$, E. J. Welton ${ }^{3}$, Y. Gu ${ }^{4}$ \\ 1. NASA GSFC-JCET, Code 612, Greenbelt, MD, USA \\ 2. Naval Research Laboratory, Monterey, CA, USA \\ 3. NASA GSFC, Code 612, Greenbelt, MD, USA \\ 4 UCLA, Los Angeles, CA, USA \\ (*) E-mail: simone.lolli@nasa.gov \\ Received: 27/04/2015 Accepted: 16/02/2016 \\ DOI: $10.7149 /$ OPA.49.1.1
}

\begin{abstract}
:
Optically thin cirrus cloud (optical depth < 0.03) net radiative effect represents one of the primary uncertainties in climate feedback, as sub-visible clouds play a fundamental role in atmospheric radiation balance and climate change. A lidar is a very sensitive optical device to detect clouds with an optical depth as low as $10^{-4}$. In this paper we assess the daytime net radiative effect of sub-visible cirrus clouds detected at Goddard Space Flight Center, a permanent observational site of the NASA Micro Pulse Lidar Network in 2012. Depending on their height, season and hour of the day, the solar albedo effect can outweigh the infrared greenhouse effect, cooling the earth-atmosphere system rather than warming it exclusively. As result, based on latitude, the net effect of sub-visible cirrus clouds can be more accurately parameterized in climate models.
\end{abstract}

Keywords: Lidar, Cirrus Clouds, Extinction coefficient, Radiative Transfer, Climate change

\section{REFERENCES AND LINKS / REFERENCIAS Y ENLACES}

[1] Sassen, K., M. Griffin and G. Dodd, "Optical scattering and microphysical properties of subvisual cirrus clouds, and climate implications" J. Appl. Meteorology, 28, 91-98 (1989) http://dx.doi.org/10.1175/1520-0450(1989)028\%3C0091:0SAMPO\%3E2.0.C0;2

[2] Jensen, E.J., O. Toon, H. Selkirk, J. Spinhirne and M. Schoeberl, "On the formation and persistence of subvisual cirrus clouds near the tropical tropopause” J. Geophys. Res., 101, 21361-21375 (1996) http://dx.doi.org/10.1029/95JD03575

[3] Solomon, S., K. H. Rosenlof, R. W. Portmann, J. S. Daniel1, S. M. Davis, T. J. Sanford, G-K Plattner, "Contributions of stratospheric water vapor to decadal changes in the rate of global warming" Science,

327, 1219-1223 (2010)

http://dx.doi.org/10.1126/science.1182488

[4] IPCC: Climate Change 2013 - The Physical Science Basis, Working Group I Contribution to the Fifth Assessment Report of the Intergovernmental Panel on Climate Change, edited by: Inter- governmental Panel on Climate Change, Cambridge University Press, Cambridge, UK and New York, NY, USA, (2014).

[5] Spang, R., G. Günther, M. Riese, L. Hoffmann, R. Müller, and S. Griessbach, " Satellite observations of cirrus clouds in the Northern Hemisphere lowermost stratosphere" Atmos. Chem. Phys. 15, 927-950, (2015)

http://dx.doi.org/10.5194/acp-15-927-2015

[6] Immler, F., Treffeisen, R., Engelbart, D., Krüger, K., and Schrems, O. "Cirrus, contrails, and ice supersaturated regions in high pressure systems at northern mid latitudes" Atmos. Chem. Phys., 8, 1689-1699, (2008) http://dx.doi.org/10.5194/acp-8-1689-2008

[7] Welton, J. R. Campbell, J. D. Spinhirne, and V. S. Scott, “ Global monitoring of clouds and aerosols using a network of micro-pulse lidar systems, in Lidar Remote Sensing for Industry and Environmental 
Monitoring" Proc. SPIE, 4153, 151-158, (2001)

http://dx.doi.org/10.1117/12.417040

[8] Lolli S., E. J Welton and J. R. Campbell, "Evaluating Light Rain Drop Size Estimates from Multiwavelength Micropulse Lidar Network Profiling” J. Atmos. Oceanic Technol., 30, 2798-2807, (2013).

http://dx.doi.org/10.1175/JTECH-D-13-00062.1

[9] Spinhirne, J.D., J. A. R. Rall, and V. S. Scott, “Compact Eye Safe Lidar Systems” Rev. Laser Eng., 23, 112118, (1995)

http://dx.doi.org/10.2184/lsj.23.112

[10] Lolli, S., L Sauvage, S Loaec, M Lardier, "EZ Lidar: A new compact autonomous eye-safe scanning aerosol lidar for extinction measurements and PBL height detection. Validation of the performances against other instruments and intercomparison campaigns" Opt. Pura Apl., 44 (1), 33-41, (2011)

[11] Campbell, J. R., K. Sassen and E. J. Welton, "Elevated cloud and aerosol layer retrievals from micropulse lidar signal profiles" J. Atmos. Oceanic Technol., 25, 685-700, (2008) http://dx.doi.org/10.1175/2007JTECHA1034.1

[12] Fernald, F. G., “Analysis of atmospheric lidar observations: Some comments,” Appl. Opt. 23, 652-653 (1984) http://dx.doi.org/10.1364/A0.23.000652

[13] Heymsfield, A., D. Winkler, M. Avery, M. Vaughan, G. Diskin, M. Deng, V. Mitev and R. Matthey et al., "Relationships between Ice Water Content and Volume Extinction Coefficient from In Situ Observations for Temperatures from $0^{\circ}$ to $-86^{\circ} \mathrm{C}$ : Implications for Spaceborne Lidar Retrievals*." J. Appl. Meteor. Climatol., 53, 479-505, (2014) http://dx.doi.org/10.1175/JAMC-D-13-087.1

[14] Fu, Q. and Liou, K. N. "On the correlated k-distribution method for radiative transfer in nonhomogeneous atmospheres” J. Atmos. Sci., 49, 2139-2156, (1992) http://dx.doi.org/10.1175/1520-0469(1992)049<2139:0TCDMF>2.0.C0;2

[15] Gu, Y. J. Farrara, K. N. Liou, and C. R. Mechoso, " Parameterization of cloud-radiation processes in the UCLA general circulation model” J. Climate, 16, 3357-3370, (2003) http://dx.doi.org/10.1175/1520-0442(2003)016<3357:POCPIT>2.0.C0;2

[16] Lolli S. and Di Girolamo P., "Principal Component Analysis Approach to Evaluate Instrument Performances in Developing a Cost-Effective Reliable Instrument Network for Atmospheric Measurements" J. Atmos. Oceanic Technol., 32, 1642-1649, (2015) http://dx.doi.org/10.1175/JTECH-D-15-0085.1

[17] Grenfell, T. C., and S. G. Warren, "Representation of a nonspherical ice particle by a collection of independent spheres for scattering and absorption of radiation" J. Geophys. Res., 104(D24), 31,69731, (1999)

http://dx.doi.org/10.1029/1999JD9004962

\section{Introduction}

Cirrus clouds, and especially optically thin ice crystal clouds with an optical depth below 0.03 exist globally [1], but are mostly found in the tropical upper troposphere, where the temperature is very low [2]. These sub-visible cirrus clouds (SVC) have been investigated over several decades both from in-situ measurements through airborne probes [3] and through ground-based lidar profiling [1]. SVC clouds are responsible for a large proportion of the uncertainties of climate change projections by Global Circulation Models (GCM). This comes from poorly understood and represented interactions and feedbacks between dynamic, microphysical and radiative processes affecting sub-visible cirrus clouds [4, 5]. A recent IPCC report (AR4) [4] shows that different climate models parameterize ice formation in a very simplified way, leading to a factor of ten in difference between zonally averaged Ice Water Content (IWC) [6]. As a consequence, climate modeling is very sensitive to small changes in cirrus coverage or ice microphysics. Large uncertainties in climate prediction caused by processes involving cirrus clouds highlight the importance of more quantitative information by observation, especially on SVC.

SVC are primary regulators of water vapor concentrations in the upper troposphere-lower stratosphere region, which plays a fundamental role in atmospheric radiation balance [3] and then climate change effects seen at the surface. Lidars are ideally sensitive to detecting clouds with an optical depth (COD) as low as $10^{-4}$. The main purpose of this study is to assess properties and the seasonal variability of daytime 
SVC net radiative effect and statistical properties, detected at Goddard Space Flight Center (GSFC), a permanent observational site of the NASA Micro Pulse Lidar NETwork (MPLNET) in 2012.

\section{Methodology}

MPLNET [7-10], is a global federated lidar network, begun in 1999, which counts more than twenty stations (deployed worldwide, from tropics, mid-latitudes, equator, Arctic and Antarctic regions) equipped with homogenous single wavelength elastic commercially available lidars. Project instruments sample the atmosphere continuously with a spatial resolution of $75 \mathrm{~m}$ and a temporal resolution of $1 \mathrm{~min}$ in all different meteorological conditions. Measurements are centrally processed in near-real time at GSFC, and are made publicly available online to the scientific community (http://mplnet.gsfc.nasa.gov).

The new Version 3 (V3) MPLNET cloud algorithm is an automated algorithm developed to retrieve singlelayer cirrus cloud extinction profile from the range-corrected elastic lidar signal. The algorithm uses sharp changes in the Signal to Noise Ratio (SNR) as threshold to detect cloud base and top. A detailed description is available in [11]. The algorithm is applied in this study to detect single-layer optically thin clouds profiled at the GSFC MPLNET site during 2012. To invert the single wavelength elastic lidar equation, we need to assume proportionality between the extinction and backscattering coefficients: the so-called lidar ratio (LR) [12]. For aerosol layers, LR shows a high variability (20sr-120sr), while for ice clouds, the extinction profile can be retrieved simultaneously at $\mathrm{LR}=20 \mathrm{sr}$ and $\mathrm{LR}=30 \mathrm{sr}$ respectively, as the potential variance within this applied solution is fully replicated [11]. All cloud samples are included, depending on the temporal sampling resolution used to resolve them in the V3 product 1,5 or 20 min averaging). SVC microphysical properties, inputs used by the radiative transfer model, are retrieved using parameterization described in [13]. The effective ice crystal diameter $D e$, calculated with an empirical formula that links the crystal effective size with temperature $T$, follows an exponential law [13]:

$$
D e=a e^{b T}
$$

where $a$ and $b$ depend on the particular temperature range. $T$ is retrieved directly from the temperature profile of WMO radiosonde, launched daily (00 and 12 UTC) nearby Sterling, Virginia ( $50 \mathrm{~km}$ from GSFC).

Radiative effect parameters are calculated with the Fu-Liou-Gu (FLG) radiative transfer code [14, 15]. FLG is a $\delta$-four stream transfer scheme for flux calculations in both solar and infrared spectra, which are divided into six and twelve bands, respectively. The $\mathrm{K}$-distribution method is used to parameterize nongray gaseous absorption by $\mathrm{CH}_{4}, \mathrm{O}_{3}, \mathrm{CO}_{2}$ and $\mathrm{H}_{2} \mathrm{O}$. Parameterization of cirrus clouds assumes hexagonal ice crystals, randomly-oriented, and combines the extinction coefficient $\alpha$ with $D_{e}$ and IWC at each range bin $r$ as:

$$
\operatorname{IWC}(r)=\frac{\alpha(r) \varrho_{i} D_{e}(r)}{3}
$$

where $\rho_{i}$ is the ice density and $\alpha$ is the extinction coefficient retrieved with the lidar. For each detected cirrus cloud, the net radiative effect is calculated subtracting the FLG run for clear sky (control, $F_{\text {clear }}$ ) from the FLG run where cloud is present $\left(F_{c l o u d}\right.$ ). De and $I W C$ are input (Eq. 1 and 2) of the FLG model at each altitude level into the cloud:

$$
F_{\text {net }}=F_{\text {cloud }}-F_{\text {clear }}
$$

Then, to understand how the net radiative effect is linked to the cloud thermodynamics and optical variables, we use principal component analysis (PCA). This technique greatly helps in reducing complexity, as it is possible through the dimensional reduction, to represent graphically each cloud as a point in a bi-dimensional space. Then we can identify the main cloud clusters with similar characteristics producing the same net radiative effect. A more detailed description of this technique can be found in [16].

In 2012, more than 10000 SVC were profiled at GSFC. Each cloud can be characterized by several variables, including the net radiative effect at TOA, optical depth, thickness, cloud position, etc (see Table 1). Each SVC can be represented as a point in a 10-dimensional space, making the visualization impossible. 
But all the variables are not independent and if we assume a linear dependence among some of them, it is possible to apply the PCA technique that through linear combinations of the initial variables can reduce the initial 10 dimensions into the two principal components that explain most of the variability of the data and each cloud is then represented as a point into a bi-dimensional space [16].

Table 1. PCA variables and their relative units

\begin{tabular}{ll}
\hline PCA variables & Units/Values \\
\hline Net cloud effect (TOA) & $\mathrm{W} / \mathrm{m}^{2}$ \\
Cloud Optical Depth & -- \\
Day Cloud/Night Cloud & 1 Day - 0 Night \\
Cloud Top Height & $\mathrm{Km}$ \\
De & $\mu \mathrm{m}$ \\
IWC & $\mathrm{g} / \mathrm{m}^{2}$ \\
Ground-Cloud Top Diff. & $\mathrm{K}$ \\
Solar Zenith Angle & $\mathrm{Deg}$ \\
Cloud Top Temp & $\mathrm{K}$ \\
Day Of the Year & -- \\
\hline
\end{tabular}

The objective of this study is to characterize the main daytime SVC yearly trend in terms of net radiative effect. For this reason, PCA technique helps us to spot higher density clusters with clouds that have characteristics that produce the same effect.

\section{Results}

Figure 1 shows the composite plot of 2012 detected clouds, where the color represents the density. Two well distinct clusters are visible. The upper strip represents daytime clouds, while the lower strip the nighttime clouds. The first component (PC1) is a linear combination of cloud top temperature, cloud top altitude, crystal average size and the temperature difference between the ground and cloud top height. This component characterizes the thermodynamic properties of SVC.

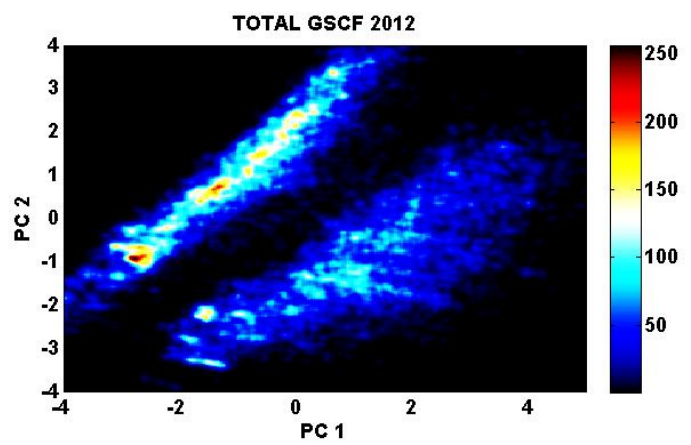

Fig. 1. SVC PCA analysis at Goddard in 2012. The two distinct patterns represent day (up) and night (down) clouds. PC 1 and PC2 are the scores related to the first and second component, linear combination of parameters described in the first column of Table 1.

SVC with higher scores on PC1 are those clouds with warmer cloud top temperatures then lower in altitude, with greater crystal size and IWC but with a lower temperature difference between ground and cloud top height. The second component (PC2) relates to net TOA cloud radiative effect, day/night flag and solar zenith angle. PC2 is thus characterized by the radiative properties of the cloud, and higher PC2 scores in Fig. 1 represent SVC with lower radiative effect (in absolute value) and lower SZA. While nighttime clouds are always warming clouds (no incoming solar radiation, then no albedo effect), daytime SVC can both cool and warm the earth-atmosphere system, depending on SZA and cloud top altitude (the former is related to the IWC and the latter to the crystal average size [17]). From the SVC subset constituted from the higher density daytime cluster (the cluster on the upper strip with a cloud density > 150, yellow-red on plot) it is calculated the SVC net radiative effect against the cloud top height, ranging from $7.5 \mathrm{~km}$ to $15 \mathrm{~km}$. Figure 2 shows how the cloud top height is triggering different forcing behavior switching from cooling to warming. The cut-off cloud top height, corresponding to a cloud neutral effect, lies at about $11.5 \mathrm{~km}$. The cloud net effect behavior can be then parameterized with a 2-degree polynomial function. 


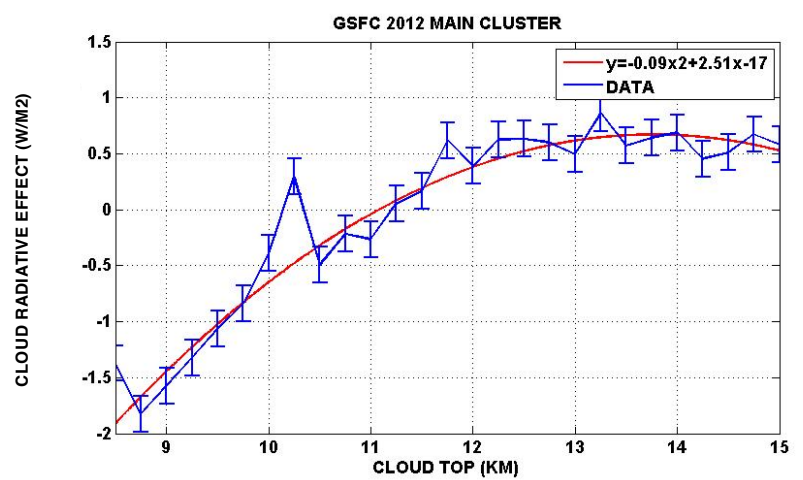

Fig. 2. Daytime main cluster (density>150) showing Net Cloud Radiative Effect vs. cloud top altitude (km). $11.5 \mathrm{~km}$ is a cut-off point where the cloud effect switches from cooling to warming. The relation between the cloud net effect and cloud top height can be approximated by a 2-degree polynomial.

If now we calculate the SVC radiative effect against the solar zenith angle (Fig. 3), we have a different behavior, as the SVC are warming the earth-atmosphere for lower SZA angles. It makes sense because for higher SZA, the path of the solar radiation into the cloud is slant, making the cloud itself optically thicker, with the albedo effect outweighing the greenhouse effect. The cut-off value, where SVC are neutral in terms of radiative effect is for a SZA about $52 \mathrm{deg}$. In this case, the relationship between the cloud net effect and the SZA is linear.

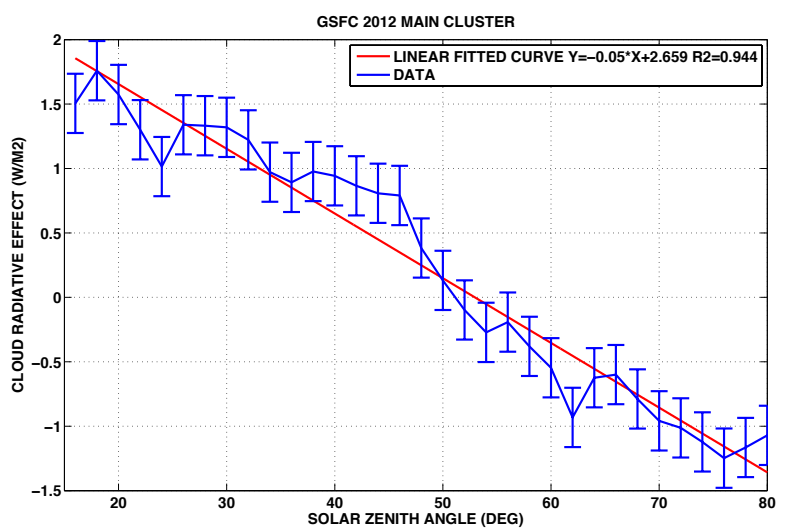

Fig. 3. Daytime main cluster (density>100) showing Net Cloud Radiative Effect (CRF) vs. Solar Zenith Angle (Deg). 52 deg is the cutoff value from which the clouds start to cool from warming. The relation between cloud net effect and SZA is linear.

During the winter season, the SVC cloud top height average is at $9.5 \mathrm{~km}$, with a SZA average of $62.5 \mathrm{deg}$. This is producing a net cooling effect of the earth-atmosphere system.

Table 2. Seasonal variability of transition point between cooling and warming (Cloud Top) and warming and cooling (SZA).

\begin{tabular}{llll}
\hline & CLOUD TOP avg & SZA avg & NET EFFECT \\
\hline DJF & $9.5 \mathrm{~km}$ & 65 & Cooling \\
MAM & $11.3 \mathrm{~km}$ & 49.2 & Slight Warming \\
JJA & $11.4 \mathrm{~km}$ & 53 & Slight Warming \\
SON & $11.7 \mathrm{~km}$ & 50 & Slight Warming \\
\hline
\end{tabular}

For spring, summer and fall, we have an opposite situation. Table 2 shows almost constant cloud top height average, while there is a difference for SZA. All the SZA values are slightly below the cut-off threshold value, then on average, SVC are slightly warming agents at Top Of the Atmosphere (TOA) during these seasons. We can speculate the existence of a gradient in forcing for SVC (coolers during the winter season and slightly warmers during the other seasons). This is due mainly on higher values of SZA during winter months with a lower cloud top height and colder temperatures (lower cloud top height and higher SZA is associated to a net cooling effect, see Figures 2 and 3 ). 


\section{Conclusions}

From new Version 3 Micro Pulse Lidar cloud products, 10000 optically thin cirrus clouds (COD <0.03) were profiled in 2012 at NASA GSFC permanent MPLNET observation site. For each cloud, net radiative effect was calculated through the FLG radiative transfer code, where the lidar retrieved cloud extinction is transformed, using parameterization in [13], into cloud IWC while the local radiosonde temperature profile into the effective crystal size $D e$. Both these variables are used as input parameters in the FLG model. The PCA technique is used to reduce dimensions and to extract a SVC daytime subset representing the cluster with more likely occurring clouds at observational site. From this subset, we calculated how the cloud radiative effect is related to the solar zenith angle and cloud top height. We found a linear relationship for the former and a 2-degree polynomial for the latter. In 2012, SVC are cooler for cloud top height lower than $11.5 \mathrm{~km}$ and for SZA above 52 degrees. Then daytime SVC, depending on position and hour of the day, are primarily atmospheric coolers or warming. Consequently, due to the higher SZA during winter months, SVC are more prone to cool the earth-atmosphere system, while the opposite is true for summer months. This study is a first step toward reducing the uncertainty in parameterization of the net radiative effect of thin cirrus cloud in global climate models. Further analysis will be performed on other years and other MPLNET permanent observational sites.

\section{Acknowledgements}

The Micro Pulse Lidar Network is supported by the NASA Earth Observing System and Radiation Sciences Programs. 